\title{
Systematic review and comparison of pharmacologic therapies for neuropathic pain associated with spinal cord injury
}

This article was published in the following Dove Press journal: Journal of Pain Research

10 July 2013

Number of times this article has been viewed

\section{Sonya J Snedecor ${ }^{\prime}$ \\ Lavanya Sudharshan' \\ Joseph C Cappelleri ${ }^{2}$ \\ Alesia Sadosky ${ }^{3}$ \\ Pooja Desai ${ }^{4}$ \\ Yash J Jalundhwala ${ }^{5}$ \\ Marc Botteman'}

'Pharmerit International, Bethesda, MD, USA; ${ }^{2}$ Global Research and Development, Pfizer, Groton, CT, USA; ${ }^{3}$ Biostatistics, Pfizer, New York, NY, USA; ${ }^{4}$ College of Pharmacy, University of Texas at Austin, Austin, TX, USA; ${ }^{5}$ Pharmacy Administration, University of Illinois at Chicago, Chicago, IL, USA

Correspondence: Sonya J Snedecor Pharmerit International, 4350 East West Highway - Suite 430, Bethesda, MD 208I4, USA

$\mathrm{Tel}+|24082| 1268$

$\mathrm{Fax}+$ I 240812 I296

Email ssnedecor@pharmerit.com
Background: Management of neuropathic pain (NeP) associated with spinal cord injury (SCI) is difficult. This report presents a systematic literature review and comparison of the efficacy and safety of pharmacologic therapies for treating SCI-associated NeP.

Methods: Medline, Embase, Cochrane, and Database of Abstracts of Reviews of Effects were searched through December 2011 for randomized, blinded, and controlled clinical trials of $\mathrm{SCI}$-associated NeP meeting predefined inclusion criteria. Efficacy outcomes of interest were pain reduction on the 11-point numeric rating scale (NRS) or $100 \mathrm{~mm}$ visual analog scale and proportion of patients achieving $\geq 30 \%$ or $\geq 50 \%$ pain reduction. Discontinuations and adverse events (AEs) were also assessed, for which Bayesian meta-analytic indirect comparisons were performed.

Results: Of the nine studies included in the analysis, samples were $<100$ patients, except for one pregabalin study $(\mathrm{n}=136)$. Standard errors for the NRS outcome were often not reported, precluding quantitative comparisons across treatments. Estimated 11-point NRS pain reduction relative to placebo was -1.72 for pregabalin, -1.65 for amitriptyline, -1.0 for duloxetine, -1 (median) for levetiracetam, -0.27 for gabapentin, 1 (median) for lamotrigine, and 2 for dronabinol. Risk ratios relative to placebo for $30 \%$ improvement were 0.71 for levetiracetam and 2.56 for pregabalin, and 0.94 and 2.91, respectively, for 50\% improvement. Meta-analytic comparisons showed significantly more AEs with pregabalin and tramadol compared with placebo, and no differences between placebo and any treatment for discontinuations.

Conclusions: Studies of SCI-associated NeP were few, small, and reported insufficient data for quantitative comparisons of efficacy. However, available data suggested pregabalin was associated with more favorable efficacy for all outcome measures examined, and that the risks of AEs and discontinuations were found to be similar among the therapies.

Keywords: neuropathic pain, spinal cord injury, systematic review, indirect comparison, pharmacologic management

\section{Introduction}

Although spinal cord injury (SCI) can result from disease, it most frequently occurs as a result of trauma, primarily from motor vehicle accidents and falls, and in the US from violence including gunshot injuries. ${ }^{1,2}$ Recent US estimates suggest that approximately 12,000 new cases of SCI occur each year, while the prevalence may be as high as 265,000 individuals. ${ }^{2}$ SCI occurs mainly among males $(80.7 \%)$ and the average age at injury is 40.7 years, ${ }^{2}$ an age of high productivity.

SCI has profound effects on patient functioning and quality of life. ${ }^{3-5}$ Neuropathic pain $(\mathrm{NeP})$, defined as "pain caused by a lesion or disease of the somatosensory 
nervous system," "6 often results from SCI, further compromising function and increasing disability. ${ }^{7}$

A variety of medications (oral and topical) are available for treating $\mathrm{NeP}$, and guidelines have been published for its treatment, ${ }^{8,9}$ including two that have focused specifically on NeP in SCI. ${ }^{10,11}$ Both of these guidelines recommend pregabalin, gabapentin, and tricyclic antidepressants as firstline therapy. Nevertheless, choosing an appropriate therapy remains challenging because of the relatively large number of medications available to treat this condition and potential differences among these medications in effectiveness or safety. An additional barrier to choosing an appropriate therapy has been the lack of comparative studies among the pharmacological options for $\mathrm{NeP}^{8}$

In the absence of comparative studies, systematic reviews that identify the potential for performing metaanalyses or indirect comparisons have helped assess the relative efficacy and safety among the therapies. However, only two formal systematic reviews in SCI have been published. ${ }^{11,12}$ The first, by Attal et al ${ }^{11}$ evaluated the level of evidence for efficacy and provided recommendations for therapy of $\mathrm{NeP}$ in patients with SCI. While pregabalin, gabapentin, and tricyclic antidepressants were all considered first-line therapy, the former was recommended with grade A evidence and the latter two with grade B evidence; strong opioids or lamotrigine were considered second- or third-line therapy. However, this review stopped short of comparing the efficacy and safety of these agents. The second systematic review included studies with mixed or unknown pain types in addition to $\mathrm{NeP},{ }^{12}$ and while it also provided graded evidence for use of medications to treat SCI pain, no comparisons were attempted.

Therefore, the primary objective of the current study was to conduct a systematic review of all available randomized clinical trials evaluating currently used pharmacologic therapies for the treatment of NeP in patients with SCI with the goal of understanding their relative efficacy and safety.

\section{Materials and methods}

\section{Data source and study selection}

This analysis was conducted as a substudy of a larger systematic review of randomized clinical trials of over 35 treatments in eight drug classes for the management of seven NeP conditions: painful diabetic neuropathy, postherpetic neuralgia, HIV-associated neuropathy, posttraumatic NeP, small-fiber NeP, SCI, central poststroke pain, and multiple sclerosisrelated pain. The substudy on painful diabetic peripheral neuropathy has already been reported separately. ${ }^{13}$
PubMed/Medline, Cochrane Database of Systematic Reviews, Cochrane Central Register of Controlled Trials, Embase, and the Database of Abstracts of Reviews of Effects were searched through December 2011. The search strategy consisted of four categories: (1) neuralgia or neuropathic pain, (2) NeP conditions of interest, (3) pharmacological treatments or classes of interest (generic or brand names), and (4) terms for randomized and blinded study designs (Table 1).

Study inclusion criteria consisted of randomized, controlled trials in SCI of adults aged $\geq 18$ years. Exclusion criteria were: fewer than 4 weeks in duration, drugs in combination with nonpharmacologic modalities, drugs administered intravenously, drugs no longer used to treat neuropathic pain, or over-the-counter agents and food supplements. Studies including patients with mixed NeP

Table I Search strategy for identifying clinical trials of pharmacologic therapies for the treatment of neuropathic pain

Search terms

I. Neuropathic pain terms: neuralgia (MeSH) OR neuropathic pain (MeSH)

\section{Drug terms}

a. Drug names: citalopram OR cipramil OR celexa OR fluoxetine OR Prozac OR sarafem OR paroxetine OR paxil OR aropax OR sertraline $O R$ zoloft $O R$ lustral OR escitalopram OR lexapro OR cipralex OR lidoderm OR (lidocaine AND [transderm* OR patch* OR skin OR cutaneous*]) OR amitriptyline OR elavil OR desipramine $O R$ norpramin $O R$ nortriptyline $O R$ pamelor $O R$ imipramine $O R$ tofranil $O R$ doxepin $O R$ sinequan $O R$ silenor OR gabapentin OR neurontin OR pregabalin OR lyrica OR carbamazepine $O R$ tegretol $O R$ carbatrol $O R$ epitol OR topiramate OR topamax OR oxacarbazepine $O R$ trileptal $O R$ lamotrigine OR lamictal OR valproic acid OR depakote OR depacon OR divalproex $O R$ epival $O R$ bupropion $O R$ trazodone $O R$ capsaicin OR methodone OR morphine OR oxycodone OR tramadol OR dronabinol $O R$ lacosamide $O R$ vimpat $O R$ phenytoin $O R$ Dilantin OR levetiracetam OR keppra OR desvenlafaxine OR pristiq OR milnacipran $O R$ savella $O R$ protriptyline $O R$ vivactil $O R$ duloxetine OR Cymbalta OR venlafaxine OR Effexor

b. Drug classes: anticonvulsant (MeSH) OR tricyclic antidepressant (MeSH) OR cannabinoids (MeSH) OR opioids (MeSH) OR serotonin reuptake inhibitor $(\mathrm{MeSH}) \mathrm{OR}$ analgesic $(\mathrm{MeSH}) \mathrm{OR}$ topical agent

3. Terms for conditions: post herpetic OR HIV (MeSH) OR HIV OR central post stroke OR spinal cord injury (MeSH) OR spinal cord injury OR diabetes (MeSH) OR diabetes OR multiple sclerosis (MeSH Terms) OR multiple (all fields) AND sclerosis (all fields) OR multiple sclerosis (all fields) OR small fiber (all fields) OR central neuropathic pain (all fields).

4. Study-design terms: (randomized controlled trial [MeSH]) OR (random allocation $[\mathrm{MeSH}]$ ) OR ([sing* OR doubl* OR trebl* OR tripl*] AND [blind* OR mask*])

Search algorithm

- \#I AND (\#2a OR \#2b OR \#3) AND \#4

Abbreviation: $\mathrm{MeSH}$, medical subject headings. 
were excluded if they did not separately report outcomes for SCI patients. Finally, results published only in abstract form (eg, as conference proceedings) were not considered, because results of studies can change substantially between initial presentation at a conference and final journal publication. ${ }^{14}$

Relevant trials were identified in a two-step process by at least two reviewers. First, reviewers independently assessed titles and abstracts of citations identified from literature searches against inclusion/exclusion criteria. Disagreements in either step were resolved by discussion and consensus. Manual searching of references included in published systematic reviews and meta-analyses was also conducted to identify additional studies, and where necessary, titles and abstracts were further reviewed for potential inclusion. Second, full-text publications of potentially relevant citations were retrieved and assessed for inclusion.

\section{Data extraction}

Quality of study reporting was evaluated using the Jadad scale, ${ }^{15}$ which measures quality of reporting for randomized controlled trials (RCTs) by assigning a numeric score ranging from 0 (poorest quality) to 5 (highest quality) according to the presence of the three key methodological criteria of randomization, blinding, and accountability of all patients, including withdrawals. The Jadad scale has been used previously for assessment of quality of clinical trials in pain. ${ }^{16,17}$ Included studies were also evaluated for potential biases, ie, patient selection bias, performance bias, detection bias, attrition bias, and reporting bias using the risk-of-bias assessment tool developed by the Cochrane Collaboration. ${ }^{18}$

Study characteristics (design, blinding, demographics, inclusion/exclusion criteria, interventions, etc) along with specific efficacy and safety data were extracted from each study into a Microsoft (Redmond, WA, USA) Access database form designed and programmed specifically for this study. Each study was extracted by three reviewers, and results were compared to ensure accuracy. Efficacy data included the change from baseline in pain severity using an 11-point numeric rating scale (NRS) or $100 \mathrm{~mm}$ visual analog scale (VAS); change in health status expressed by the EuroQol five-dimension (EQ-5D) health-state index; and the proportion of patients achieving pain reductions $\geq 30 \%$ and $\geq 50 \%$, which are considered of clinical relevance and are recommended by the Initiative on Methods, Measurement, and Pain Assessment in Clinical Trials (IMMPACT) for assessment in chronic pain clinical trials. ${ }^{19}$ Safety data included total number of adverse events (AEs) and subject withdrawals.

\section{Analyses}

Treatment effects for the 11-point NRS, $100 \mathrm{~mm}$ VAS, and EQ-5D index were calculated as the difference between active comparator and placebo for the change from baseline to end point on the pain scale or EQ-5D index. Studies reporting pain outcomes on a $10-\mathrm{cm}$ VAS were considered equivalent to an 11-point NRS to allow for comparisons across studies. Because of the small number of studies and lack of reporting of the standard error or other uncertainty measures, the weighted average was calculated as a summary measure of outcomes and treatments associated with more than one study.

For the number of patients achieving pain reductions $\geq 30 \%$ and $\geq 50 \%$ on the NRS or VAS and for AEs and withdrawals, treatment effects were calculated as the risk ratio of the event relative to placebo. For drugs with more than one identified study, the overall risk ratios (and $95 \%$ confidence intervals [CIs]) were calculated using a fixed-effect meta-analysis (Mantel-Haenszel method). Simultaneous comparisons of all drugs versus placebo were performed using a Bayesian fixed-effect indirect treatment comparison model for risk of withdrawals and occurrence of AEs.

\section{Results}

\section{Study identification and inclusion}

Figure 1 presents a flow diagram for study selection. Out of 1898 unique records identified and screened, 262 articles were assessed for eligibility and 131 articles across all NeP conditions were considered for inclusion based on the prespecified criteria, including twelve RCTs that evaluated medications for $\mathrm{NeP}$ in patients with $\mathrm{SCI}$.

Of the twelve RCTs on NeP in SCI, more than half of the studies $(n=7,58 \%)$ were of crossover design and samples included $<100$ patients (10-84 patients), except for one pregabalin study with an enrollment of 136 individuals (Table 2). The overall Jadad score for the twelve RCTs was 4.5 , and quality was high $(\geq 4)$ for all studies, except for one study (mexiletine) that received a score of 2 .

Upon further review of the twelve studies, three were subsequently excluded: two of gabapentin and one of amitriptyline. The amitriptyline study was excluded for evaluating a mixedpain population without specific analysis of the NeP-in-SCI population. ${ }^{20}$ One gabapentin study was excluded for ethical reasons for disallowance of concomitant analgesic medications 


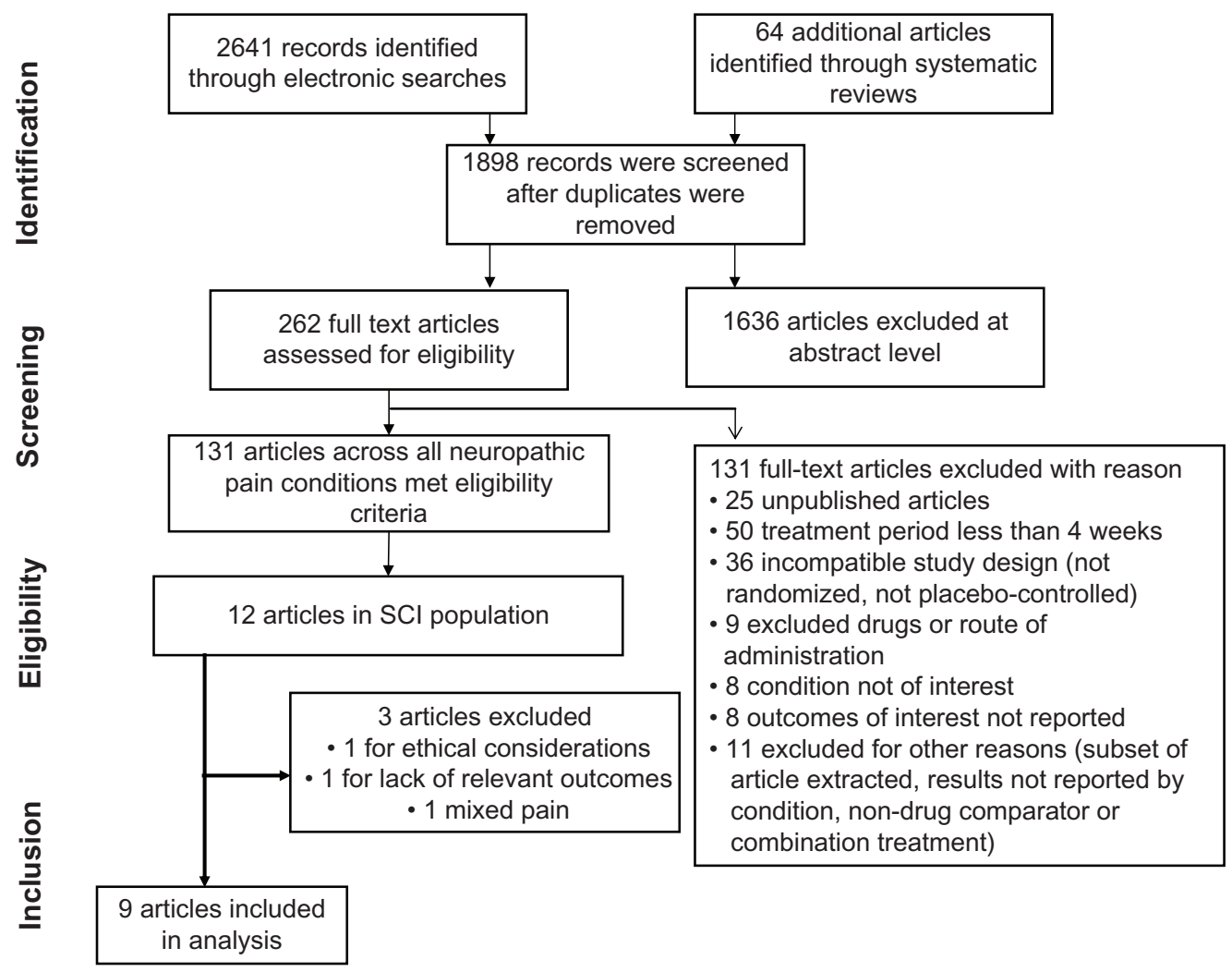

Figure I Flow diagram of study selection.

Abbreviation: $\mathrm{SCl}$, spinal cord injury.

such as ibuprofen or acetaminophen at least 15 days before and during the study ${ }^{24}$ All other studies permitted the use of stable doses of concomitant analgesic medication, acknowledging the severity of NeP in patients with SCI. The other gabapentin study did not report outcomes relevant to this review. ${ }^{29}$
Among the nine remaining RCTs, there appeared to be an overall low potential for selection and performance bias (Table 3). However, two studies had high attrition bias, and most of the studies were unclear regarding detection bias resulting from unblinding.

Table 2 Characteristics of studies evaluating medications for the treatment of neuropathic pain in patients with spinal cord injury. All trials were placebo controlled

\begin{tabular}{|c|c|c|c|c|c|c|c|c|}
\hline Study & Country & Design & $\mathbf{n}$ & $\begin{array}{l}\text { Medication evaluated } \\
\text { (maximum daily dose) }\end{array}$ & $\begin{array}{l}\text { Treatment } \\
\text { duration }\end{array}$ & $\begin{array}{l}\text { Mean pain duration, } \\
\text { months }\end{array}$ & $\begin{array}{l}\text { Mean age, } \\
\text { years }\end{array}$ & $\begin{array}{l}\text { Jadad } \\
\text { score }\end{array}$ \\
\hline Cardenas et $\mathrm{al}^{20, \mathrm{a}}$ & US & Parallel & 84 & Amitriptyline (125 mg) & 6 weeks & 168.3 & 41.4 & 4 \\
\hline Chiou-Tan et $\mathrm{al}^{21}$ & US & Crossover & II & Mexiletine (450 mg) & 4 weeks & Not stated & 44 & 2 \\
\hline Finnerup et $\mathrm{al}^{22}$ & Denmark & Crossover & 30 & Lamotrigine (400 mg) & 9 weeks & 84 & 49 & 5 \\
\hline Finnerup et $\mathrm{al}^{23}$ & Denmark & Crossover & 36 & Levetiracetam (3000 mg) & 5 weeks & Not stated & 52.8 & 5 \\
\hline Levendoglu et $\mathrm{al}^{24, \mathrm{~b}}$ & Turkey & Crossover & 20 & Gabapentin (3600 mg) & 8 weeks & 15.8 & 35.9 & 4 \\
\hline $\begin{array}{l}\text { Norrbrink and } \\
\text { Lundeberg }^{25}\end{array}$ & Sweden & Parallel & 35 & Tramadol (400 mg) & 4 weeks & Not stated & 51.3 & 4 \\
\hline Rintala et $\mathrm{al}^{26}$ & US & Crossover & 38 & $\begin{array}{l}\text { Amitriptyline (150 mg) } \\
\text { Gabapentin (3600 mg) }\end{array}$ & 8 weeks & 91.8 & 40.8 & 5 \\
\hline Rintala et $\mathrm{al}^{27}$ & US & Crossover & 7 & Dronabinol (20 mg) & 47 days & Not stated & 50.1 & 5 \\
\hline Siddall et $\mathrm{al}^{28}$ & Australia & Parallel & 136 & Pregabalin (600 mg) & 12 weeks & 121.8 & 50.1 & 5 \\
\hline Tai et $\mathrm{al}^{29, \mathrm{c}}$ & US & Crossover & 7 & Gabapentin (I800 mg) & 4 weeks & Not stated & 35.9 & 5 \\
\hline Vranken et $\mathrm{al}^{30}$ & Netherlands & Parallel & 40 & Pregabalin (600 mg) & 4 weeks & Not stated & 54.5 & 5 \\
\hline Vranken et $\mathrm{al}^{|3|}$ & Netherlands & Parallel & 48 & Duloxetine (120 mg) & 8 weeks & 60 months (median) & 50.4 & 5 \\
\hline
\end{tabular}

Notes: ${ }^{a}$ Excluded due to mixed-pain patient population; bexcluded due to prohibition of concomitant analgesic use; 'excluded due to no outcomes of interest reported. 
Table 3 Analysis for bias in the included studies

\begin{tabular}{|c|c|c|c|c|c|c|c|}
\hline Study & $\begin{array}{l}\text { Random } \\
\text { sequence } \\
\text { generation } \\
\text { (selection bias) }\end{array}$ & $\begin{array}{l}\text { Allocation } \\
\text { concealment } \\
\text { (selection bias) }\end{array}$ & $\begin{array}{l}\text { Blinding of } \\
\text { participants } \\
\text { and personnel } \\
\text { (performance bias) }\end{array}$ & $\begin{array}{l}\text { Blinding } \\
\text { of outcome } \\
\text { assessment } \\
\text { (detection bias) }\end{array}$ & $\begin{array}{l}\text { Incomplete } \\
\text { outcome data } \\
\text { (attrition bias) }\end{array}$ & $\begin{array}{l}\text { Selective } \\
\text { reporting } \\
\text { (reporting } \\
\text { bias) }\end{array}$ & $\begin{array}{l}\text { Other } \\
\text { bias }\end{array}$ \\
\hline Chiou-Tan et $\mathrm{al}^{2 !}$ & Unclear & Unclear & Unclear & Unclear & High & Unclear & Unclear \\
\hline Finnerup et $\mathrm{al}^{22}$ & Low & Low & Low & Low & Unclear & Low & Unclear \\
\hline Finnerup et $\mathrm{al}^{23}$ & Low & Low & Low & Low & Unclear & Low & Unclear \\
\hline $\begin{array}{l}\text { Norrbrink and } \\
\text { Lundeberg }^{25}\end{array}$ & Unclear & Low & Unclear & Unclear & Unclear & Unclear & Unclear \\
\hline Rintala et $\mathrm{al}^{26}$ & Low & Unclear & Unclear & Unclear & Low & Low & Unclear \\
\hline Rintala et $\mathrm{al}^{27}$ & Low & Low & Low & Unclear & High & Unclear & Unclear \\
\hline Siddall et $\mathrm{al}^{28}$ & Low & Low & Unclear & Unclear & Unclear & Low & Unclear \\
\hline Vranken et $\mathrm{al}^{30}$ & Low & Low & Low & Unclear & Unclear & Low & Unclear \\
\hline Vranken et $\mathrm{al}^{31}$ & Low & Low & Low & Low & Low & Low & Unclear \\
\hline
\end{tabular}

\section{Efficacy outcomes}

The 11-point NRS was reported as a continuous measure of pain in eight of the studies, and treatment effects could be estimated for seven (Table 4). Only one study reported a measure of uncertainty associated with the outcome. Treatment effects worse than placebo were reported for dronabinol (+2) and lamotrigine ( +1 ; median) on the 11-point NRS (Table 4). Among the medications that did demonstrate pain reduction compared with placebo, pregabalin had the largest treatment effect, with a weighted mean of -1.72 from two studies (individual treatment effects of -1.53 and -2.4 ), followed by amitriptyline, with a treatment effect of -1.65 based on a single study. For the single study of pregabalin that evaluated pain severity using the $100 \mathrm{~mm}$ VAS, the estimated treatment effect was -17.6 relative to placebo over 12 weeks (Table 4).

The EQ-5D was included in two studies of pregabalin and duloxetine. Only the pregabalin data were associated with positive outcomes on health status (Table 4).

The proportion of patients achieving $\geq 30 \%$ and $\geq 50 \%$ pain reduction was reported in two studies, one of levetiracetam and one of pregabalin. Pregabalin was significantly associated with a greater than twofold likelihood of achieving $\geq 30 \%$ and $\geq 50 \%$ pain reduction relative to placebo, with risk ratios of 2.6 (95\% CI 1.4-4.7) and 2.9 (95\% CI 1.1-7.6) for these thresholds, respectively (Figure 2). In contrast, the relative risks associated with levetiracetam approximated 1 , indicating an effect similar to placebo.

\section{Safety outcomes}

The risk ratios for all-cause discontinuations among the studies ranged from 0.6 for lamotrigine to 3 for duloxetine (Table 5), although none was found to be significantly different than placebo. More than one data point was
Table 4 Continuous efficacy outcomes of pain reduction and health status compared with placebo among the included studies

\begin{tabular}{|c|c|c|c|}
\hline Study & $\begin{array}{l}\text { Mean } \\
\text { baseline } \\
\text { score }\end{array}$ & $\begin{array}{l}\text { Treatment } \\
\text { effect }^{a}\end{array}$ & $95 \% \mathrm{Cl}$ \\
\hline \multicolumn{4}{|l|}{ I I-point NRS } \\
\hline $\begin{array}{l}\text { Amitriptyline: } \\
\text { Rintala et } a^{26}\end{array}$ & 5.6 & $-1.65^{b}$ & - \\
\hline Dronabinol: Rintala et $\mathrm{al}^{27}$ & - & 2 & - \\
\hline Duloxetine: Vranken et $\mathrm{a}^{31}$ & 7.15 & -1 & - \\
\hline Gabapentin: Rintala et $\mathrm{al}^{26}$ & 5.6 & $-0.27^{\mathrm{b}}$ & - \\
\hline $\begin{array}{l}\text { Lamotrigine: } \\
\text { Finnerup et } \mathrm{al}^{22}\end{array}$ & - & I (median) & - \\
\hline $\begin{array}{l}\text { Levetiracetam: } \\
\text { Finnerup et } \mathrm{a}^{23}\end{array}$ & 6 (median) & $-I$ (median) & - \\
\hline $\begin{array}{l}\text { Mexiletine: } \\
\text { Chiou-Tan et } \mathrm{al}^{21}\end{array}$ & 8.4 & $\begin{array}{l}\text { Could not be } \\
\text { calculated }\end{array}$ & - \\
\hline Pregabalin: Siddall et al ${ }^{28}$ & 6.63 & -1.53 & $\begin{array}{l}(-0.92 \\
-2.15)\end{array}$ \\
\hline Pregabalin: Vranken et a ${ }^{30}$ & 7.5 & -2.4 & - \\
\hline $\begin{array}{l}\text { Pregabalin: weighted } \\
\text { average } \\
100 \text { mm VAS }\end{array}$ & - & -1.72 & - \\
\hline $\begin{array}{l}\text { Pregabalin: Siddall et al }{ }^{28} \\
\text { EQ-5D }\end{array}$ & 71.07 & -17.6 & - \\
\hline $\begin{array}{l}\text { Pregabalin: Vranken et a }{ }^{30} \\
\text { (EQ-5D index) }\end{array}$ & - & $0.4 \mathrm{I}$ (median) & - \\
\hline $\begin{array}{l}\text { Pregabalin: Vranken et al }{ }^{30} \\
\text { (EQ-5D VAS) }\end{array}$ & 55.25 & 17.6 & - \\
\hline $\begin{array}{l}\text { Duloxetine: Vranken et } \mathrm{al}^{31} \\
\text { (EQ-5D index) }\end{array}$ & 0.3 & -0.09 & - \\
\hline $\begin{array}{l}\text { Duloxetine: Vranken et a }{ }^{31} \\
\text { (EQ-5D VAS) }\end{array}$ & 59.50 & -1 & - \\
\hline
\end{tabular}

Notes: a Negative treatment effects on the I I-point NRS and $100 \mathrm{~mm}$ VAS indicate net improvement over that of placebo, negative treatment effects on the EQ-5D indicate worsening; bvalues are only for patients who completed all three crossover phases of the study.

Abbreviations: $\mathrm{Cl}$, confidence interval; EQ-5D, EuroQol five-dimension qualityof-life measure; NRS, numerical rating scale; VAS, visual analog scale. 


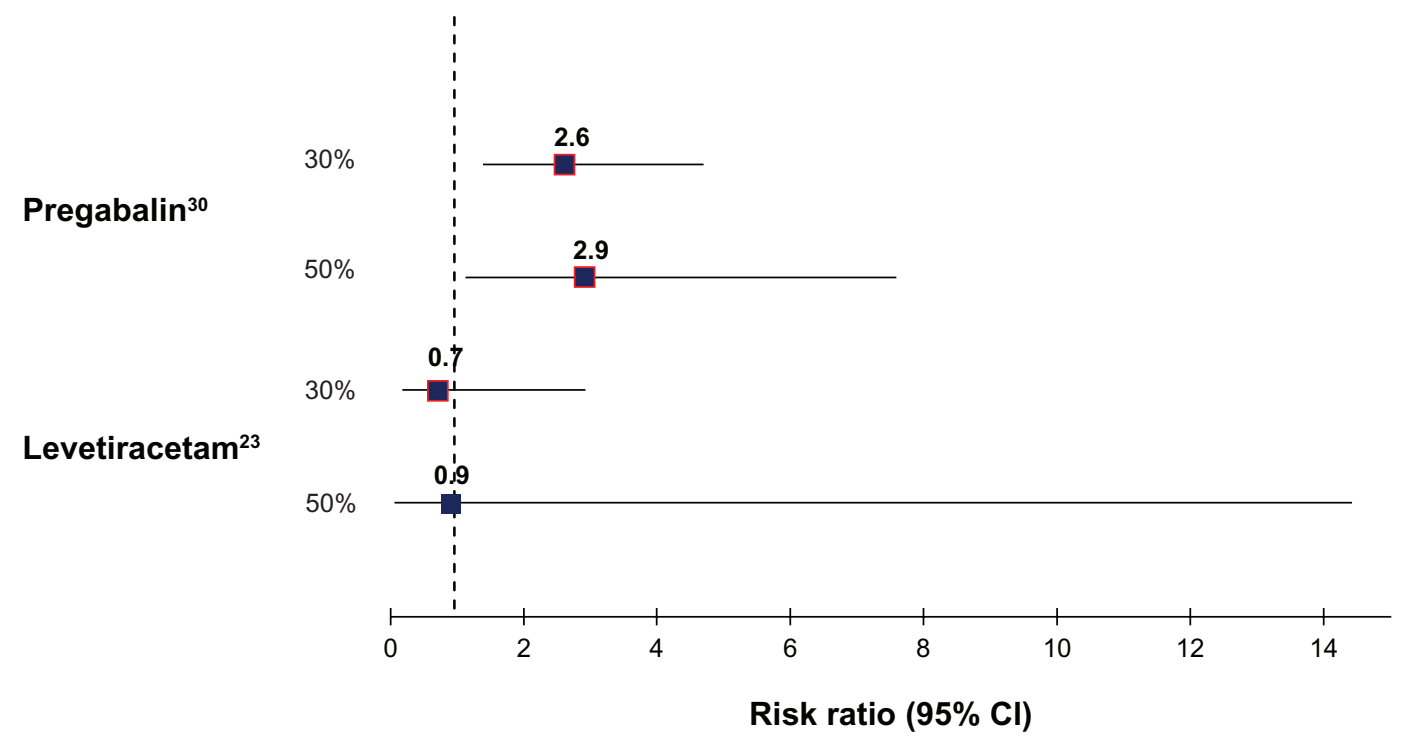

Figure 2 Relative risk for achieving $\geq 30 \%$ and $\geq 50 \%$ reduction in pain compared with placebo.

Abbreviation: $\mathrm{Cl}$, confidence interval.

available for pregabalin, and the combined discontinuation risk favored this treatment relative to placebo $(0.68,95 \% \mathrm{CI}$ 0.44-1.04) (Figure 3), with a trend toward statistical significance $(P=0.07)$. An indirect comparison for discontinuations using a Bayesian fixed-effect model (Figure 4) affirmed no significant differences between placebo and any of the medications, although pregabalin had the most favorable (lowest)

Table 5 Risk ratios relative to placebo for discontinuations and adverse event outcomes among the included studies

\begin{tabular}{|c|c|c|}
\hline \multirow[t]{2}{*}{ Study } & \multicolumn{2}{|c|}{ Risk Ratio (95\% confidence interval) } \\
\hline & Discontinuations & Adverse events \\
\hline \multicolumn{3}{|l|}{ Amitriptyline } \\
\hline Rintala et $\mathrm{a}^{26}$ & $1.06(0.4-2.82)$ & - \\
\hline \multicolumn{3}{|l|}{ Dronabinol } \\
\hline Rintala et $\mathrm{a}^{27}$ & I (0.08-13.02) & - \\
\hline \multicolumn{3}{|l|}{ Duloxetine } \\
\hline Vranken et $\mathrm{al}^{31}$ & $3(0.34-26.84)$ & - \\
\hline \multicolumn{3}{|l|}{ Gabapentin } \\
\hline Rintala et $\mathrm{a}^{26}$ & $0.97(0.35-2.68)$ & - \\
\hline \multicolumn{3}{|l|}{ Lamotrigine } \\
\hline Finnerup et $\mathrm{a}^{22}$ & $0.6(0.16-2.21)$ & $0.96(0.56-1.65)$ \\
\hline \multicolumn{3}{|l|}{ Levetiracetam } \\
\hline Finnerup et $\mathrm{a}^{23}$ & $2.82(0.84-9.5 \mathrm{I})$ & $1.20(0.64-2.24)$ \\
\hline \multicolumn{3}{|l|}{ Mexiletine } \\
\hline Chiou-Tan et $\mathrm{al}^{21}$ & $\mathrm{I}(0.3 \mathrm{I}-3.28)$ & - \\
\hline \multicolumn{3}{|l|}{ Pregabalin } \\
\hline Siddall et $\mathrm{al}^{28}$ & $0.67(0.43-1.05)$ & $1.28(I . I I-1.49)$ \\
\hline Vranken et $\mathrm{al}^{30}$ & $0.75(0.19-2.93)$ & - \\
\hline Overall risk ratio & $0.68(0.44-1.04)$ & - \\
\hline \multicolumn{3}{|l|}{ Tramadol } \\
\hline Norrbrink and & $2.87(0.75-10.91)$ & $1.57(0.95-2.57)$ \\
\hline Lundeberg ${ }^{25}$ & & \\
\hline
\end{tabular}

Note: aEstimated using Mantel-Haenszel method. mean risk $(0.64,95 \%$ CI $0.36-1.03)$ and tramadol had the least favorable (2.49, 95\% CI 1.01-4.07).

Among the studies for which the risk of AEs could be estimated (Table 5), the risk ratios relative to placebo ranged from 0.96 for lamotrigine to 1.57 for tramadol. Only pregabalin had a relative risk of AEs significantly higher than placebo based on the published data (risk ratio 1.28, 95\% CI 1.11-1.49). The Bayesian fixed-effect indirect comparison, which adjusts for placebo responses in each trial, resulted in significant differences from placebo for pregabalin and tramadol (Figure 5), with mean risks of 1.47 (95\% CI 1.25-1.71) and 1.45 (95\% CI 1.12-1.72), respectively.

\section{Discussion}

Only twelve RCTs were identified in our systematic review, of which nine could be included in a qualitative and/or quantitative comparative analysis. A 2009 systematic review by Attal et al ${ }^{11}$ of pharmacologic management of $\mathrm{NeP}$ in patients with SCI, which included treatment recommendations, also noted that very few studies have specifically evaluated this pain condition. The results reported here demonstrate that there is still a lack of clinical studies as well as a dearth of comparative data among the identified pharmacologic therapies. While the quality of these studies could be considered high based on the Jadad criteria, the reported data were often missing uncertainty measures, such as CIs or standard error surrounding the mean outcomes, precluding inclusion into a comparative meta-analysis.

Identified studies were often performed in very small populations, which also potentially reduced the reliability of their 


\begin{tabular}{|c|c|c|c|c|c|c|}
\hline Study or subgroup & Events & Total & Events & Total & Weight & $\mathrm{M}-\mathrm{H}$, fixed, $95 \% \mathrm{C}$ \\
\hline Siddall ${ }^{28}$ & 21 & 70 & 30 & 67 & $88.5 \%$ & $0.67[0.43,1.05]$ \\
\hline Vranken ${ }^{30}$ & 3 & 20 & 4 & 20 & $11.5 \%$ & $0.75[0.19,2.93]$ \\
\hline Total $(95 \% \mathrm{Cl})$ & & 90 & & 87 & $100.0 \%$ & $0.68[0.44,1.04]$ \\
\hline Total events & 24 & & 34 & & & \\
\hline \multicolumn{7}{|c|}{ Heterogeneity: $\mathrm{Chi}^{2}=0.02, \mathrm{df}=1(P=0.88) ;\left.\right|^{2}=0 \%$} \\
\hline \multicolumn{7}{|c|}{ Test for overall effect: $Z=1.78(P=0.07)$} \\
\hline
\end{tabular}

Figure 3 Forest plot of discontinuation rates relative to placebo for pregabalin. Abbreviations: $\mathrm{Cl}$, confidence interval; $\mathrm{M}-\mathrm{H}$, Mantel-Haenszel method.

results and the value of their contribution within comparative analyses. Larger studies are needed for different treatments, such as the recent publication assessing neuropathic pain in SCI. ${ }^{32}$ Pregabalin was the only treatment with available data from two studies, and with an 11-point NRS treatment effect had the largest effect size of all the evaluated medications. Notably, one of the pregabalin studies also had the largest sample size of all the studies: a possible explanation for the identification of statistically significant results.

Only two studies reported EQ-5D outcomes for pregabalin and duloxetine. While several of the studies assessed health-related quality of life using the Short Form (36) Health Survey, a measure consisting of six distinct domains and two summary scales, the EQ-5D measure was chosen for the current analysis. This choice was based on the fact that the EQ-5D is measured on a single continuous scale and
$\mathrm{M}-\mathrm{H}$, fixed, $95 \% \mathrm{Cl}$

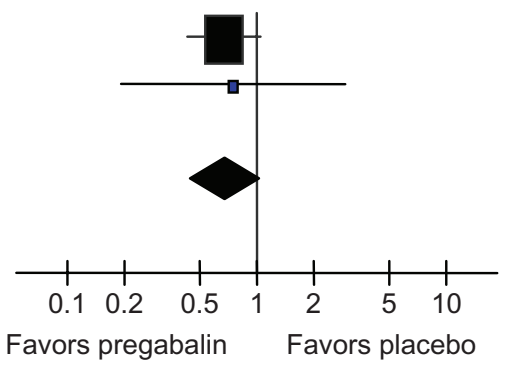

would have been amenable to quantitative meta-analysis had sufficient data been identified.

None of the studies reported risk of all-cause discontinuations greater than placebo. However, a significantly higher risk of AEs relative to placebo was observed for several treatments. Therefore, it may be hypothesized that despite AEs, patients remain on therapy due to beneficial treatment effects.

Several limitations of this review should be noted. Only a small number of studies met inclusion criteria, and their sample sizes were generally small $(<50)$. Additionally, only RCTs were included, and while this type of study minimizes bias, results may not necessarily reflect clinical practice; many of the RCTs were of short duration (maximum of 12 weeks) and longer-term treatment is likely to be required in the clinical setting.

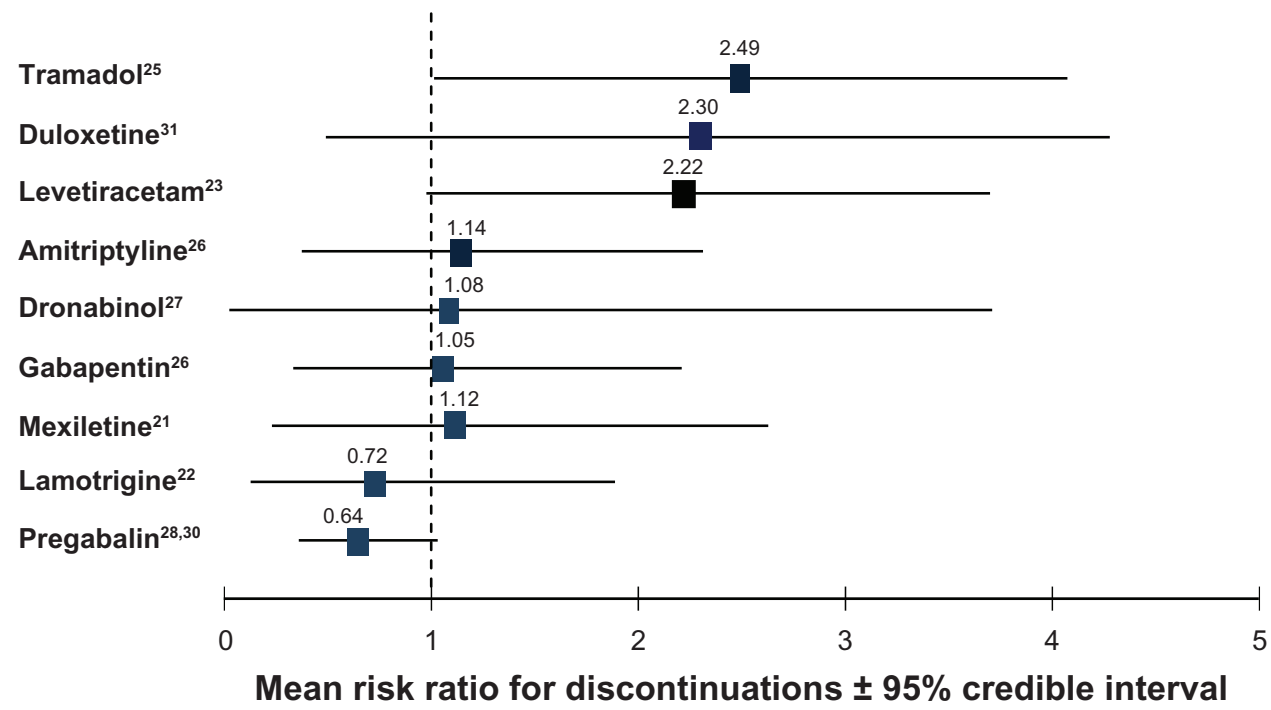

Favors comparator Favors placebo

Figure 4 Bayesian fixed-effect model for indirect comparison of mean effects for discontinuations; $95 \%$ credible interval signifies the range within which $95 \%$ of sample estimates fall. 


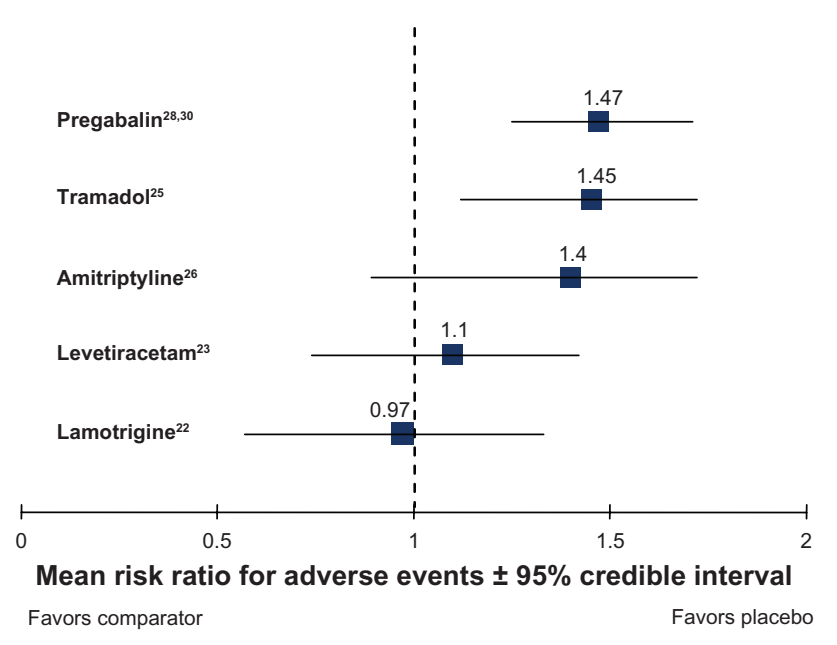

Figure 5 Bayesian fixed-effect model for indirect comparison of mean effects for incidence of adverse events; $95 \%$ credible interval signifies the range within which $95 \%$ of sample estimates fall.

This study evaluated only the 11-point NRS and $100 \mathrm{~mm}$ VAS outcomes as measures of efficacy. Not every study reported one of these outcomes and several studies also reported other efficacy measures, such as clinical global impression of change, patient global impression of change, or global assessment of therapeutic effect. These more qualitative measures could potentially provide additional therapeutic evidence not captured by this analysis.

An important limitation with regard to safety is that discontinuations due to all causes were analyzed. No differences in discontinuations were observed between any treatment and placebo, although had the discontinuation analyses been separated into discontinuations due to lack of efficacy and due to AEs, it is possible that significant differences for some treatments would have been observed. Additionally, it should be noted that two studies used diphenhydramine as placebo, ${ }^{26,27}$ in order to mimic some of the side effects often associated with their active comparators. Therefore, differences in AEs and discontinuations between diphenhydramine and the active comparators (amitriptyline, gabapentin, and dronabinol) may be less than the differences between placebo and active treatments of other studies.

In conclusion, this systematic review compiles the best available evidence for the treatment of $\mathrm{NeP}$ associated with SCI and demonstrates a substantial need for comparative studies of pharmacologic therapies for this chronic pain condition. To make proper efficacy comparisons among treatments, one must consider sample size, study design (parallel or crossover), statistical analysis methods, and efficacy outcomes for comparability. However, the published studies identified for this analysis were generally small and lacked data for performing adequate meta-analyses or quantitative comparisons. Pregabalin was the treatment most studied, and was associated with favorable efficacy for all outcome measures examined. Given the limitations of the data reported in the studies included in this review, definitive lack of efficacy for the other identified treatments could not be demonstrated.

\section{Acknowledgments}

The authors gratefully acknowledge Ewan Cobran, Sonam Mehta, and Yi-Ting Tsai of Pharmerit International for extraction of data from the studies, and E Jay Bienen for providing editorial assistance, which was funded by Pfizer Inc.

\section{Disclosure}

This study was funded by Pfizer. Sonya J Snedecor, Lavanya Sudharshan, Pooja Desai, Yash Jalundhwala, and Marc Botteman were employees of Pharmerit International at the time this study was conducted and were paid consultants to Pfizer in connection with the development of this manuscript and the study that it describes. Joseph C Cappelleri and Alesia Sadosky are employees and shareholders of Pfizer, the sponsor of this study.

\section{References}

1. van den Berg ME, Castellote JM, Mahillo-Fernandez I, de Pedro-Cuesta J. Incidence of spinal cord injury worldwide: a systematic review. $\mathrm{Neu}$ roepidemiology. 2010;34(3):184-192.

2. National Spinal Cord Injury Statistical Center. Spinal Cord Injury Facts and Figures at a Glance. Birmingham (AL): National SCI Statistical Center; 2013. Available from: https://www.nscisc.uab.edu/ PublicDocuments/fact_figures_docs/Facts\%202013.pdf. Accessed June 4, 2013.

3. Westgren N, Levi R. Quality of life and traumatic spinal cord injury. Arch Phys Med Rehabil. 1998;79(11):1433-1439.

4. Leduc BE, Lepage Y. Health-related quality of life after spinal cord injury. Disabil Rehabil. 2002;24(4):196-202.

5. Migliorini CE, New PW, Tonge BJ. Quality of life in adults with spinal cord injury living in the community. Spinal Cord. 2011;49(3): 365-370.

6. Treede RD, Jensen T, Campbell JN, et al. Neuropathic pain: redefinition and a grading system for clinical and research purposes. Neurology. 2008;70(18):1630-1635.

7. Jensen MP, Chodroff MJ, Dworkin RH. The impact of neuropathic pain on health-related quality of life: review and implications. Neurology. 2007;68(15):1178-1182.

8. Attal N, Cruccu G, Baron R, et al. EFNS guidelines on the pharmacological treatment of neuropathic pain: 2010 revision. Eur J Neurol. 2010;17(9):1113-1123, e67-e88.

9. Dworkin RH, O'Connor AB, Audette J, et al. Recommendations for the pharmacological management of neuropathic pain: an overview and literature update. Mayo Clin Proc. 2010;85(3 Suppl):S3-S14.

10. Baastrup C, Finnerup NB. Pharmacological management of neuropathic pain following spinal cord injury. CNS Drugs. 2008;22(6):455-475.

11. Attal N, Mazaltarine G, Perrouin-Verbe B, Albert T. Chronic neuropathic pain management in spinal cord injury patients. What is the efficacy of pharmacological treatments with a general mode of administration? (Oral, transdermal, intravenous). Ann Phys Rehabil Med. 2009;52(2):124-141. 
12. Teasell RW, Mehta S, Aubut JA, et al. A systematic review of pharmacologic treatments of pain after spinal cord injury. Arch Phys Med Rehabil. 2010;91(5):816-831.

13. Snedecor SJ, Sudharshan L, Cappelleri JC, Sadosky A, Mehta S, Botteman M. Systematic review and meta-analysis of pharmacological therapies for painful diabetic peripheral neuropathy. Pain Pract. [Epub March 28, 2013.]

14. Moher D, Liberati A, Tetzlaff J, Altman DG. Preferred reporting items for systematic reviews and meta-analyses: the PRISMA statement. BMJ. 2009;339:b2535.

15. Jadad AR, Moore RA, Carroll D, et al. Assessing the quality of reports of randomized clinical trials: is blinding necessary? Control Clin Trials. 1996;17(1):1-12.

16. Watson CP, Gilron I, Sawynok J. A qualitative systematic review of head-to-head randomized controlled trials of oral analgesics in neuropathic pain. Pain Res Manag. 2010;15(3):147-157.

17. Vargas-Espinosa ML, Sanmartí-Garcia G, Vázquez-Delgado E, GayEscoda C. Antiepileptic drugs for the treatment of neuropathic pain a systematic review. Med Oral Patol Oral Cir Bucal. 2012;17(5): e786-e793.

18. Higgins JP, Altman DG, Gotzsche PC, et al. The Cochrane Collaboration's tool for assessing risk of bias in randomised trials. BMJ. 2011;343:d5928.

19. Dworkin RH, Turk DC, Farrar JT, et al. Core outcome measures for chronic pain clinical trials: IMMPACT recommendations. Pain. 2005;113(1-2):9-19.

20. Cardenas D, Warms C, Turner J, Marshall H, Brooke M, Loeser JD. Efficacy of amitriptyline for relief of pain in spinal cord injury: results of a randomized controlled trial. Pain. 2002;96(3):365-373.

21. Chiou-Tan F, Tuel S, Johnson J, Priebe MM, Hirsh D, Strayer J. Effect of mexiletine on spinal cord injury dysesthetic pain. Am J Phys Med Rehabil. 1996;75(2):84-87.

22. Finnerup N, Sindrup S, Bach F, Johannesen I, Jensen T. Lamotrigine in spinal cord injury pain: a randomized controlled trial. Pain. 2002;96(3): 375-383.
23. Finnerup NB, Grydehøj J, Bing J, et al. Levetiracetam in spinal cord injury pain: a randomized controlled trial. Spinal Cord. 2009;47(12): 861-867.

24. Levendoglu F, Ogün C, Ozerbil O, Ogün T, Ugurlu H. Gabapentin is a first line drug for the treatment of neuropathic pain in spinal cord injury. Spine. 2004;29(7):743-751.

25. Norrbrink C, Lundeberg T. Tramadol in neuropathic pain after spinal cord injury: a randomized, double-blind, placebo-controlled trial. Clin J Pain. 2009;25(3):177-184.

26. Rintala DH, Holmes SA, Courtade D, Fiess RN, Tastard LV, Loubser PG. Comparison of the effectiveness of amitriptyline and gabapentin on chronic neuropathic pain in persons with spinal cord injury. Arch Phys Med Rehabil. 2007;88(12):1547-1560.

27. Rintala DH, Fiess RN, Tan G, Holmes SA, Bruel BM. Effect of dronabinol on central neuropathic pain after spinal cord injury: a pilot study. Am J Phys Med Rehabil. 2010;89(10):840-848.

28. Siddall P, Cousins M, Otte A, Griesing T, Chambers R, Murphy TK Pregabalin in central neuropathic pain associated with spinal cord injury: a placebo-controlled trial. Neurology. 2006;67(10):1792-1800.

29. Tai Q, Kirshblum S, Chen B, Millis S, Johnston M, DeLisa J. Gabapentin in the treatment of neuropathic pain after spinal cord injury: a prospective, randomized, double-blind, crossover trial. J Spinal Cord Med. 2002;25(2):100-105.

30. Vranken JH, Dijkgraaf MG, Kruis MR, van der Vegt MH, Hollmann MW, Heesen M. Pregabalin in patients with central neuropathic pain: a randomized, double-blind, placebo-controlled trial of a flexible-dose regimen. Pain. 2008;136(1-2):150-157.

31. Vranken JH, Hollmann MW, van der Vegt MH, et al. Duloxetine in patients with central neuropathic pain caused by spinal cord injury or stroke: a randomized, double-blind, placebo-controlled trial. Pain. 2011;152(2):267-273.

32. Cardenas DD, Nieshoff EC, Sanin L, et al. A randomized trial of pregabalin in patients with neuropathic pain due to spinal cord injury. Neurology. 2013;80(6):533-539.
Journal of Pain Research

\section{Publish your work in this journal}

The Journal of Pain Research is an international, peer-reviewed, open access, online journal that welcomes laboratory and clinical findings in the fields of pain research and the prevention and management of pain. Original research, reviews, symposium reports, hypothesis formation and commentaries are all considered for publication.

\section{Dovepress}

The manuscript management system is completely online and includes a very quick and fair peer-review system, which is all easy to use. Visit http://www.dovepress.com/testimonials.php to read real quotes from published authors. 